\title{
Immune Checkpoint Inhibitors in Urothelial Bladder Cancer: State of the Art and Future Perspectives
}

\author{
Giandomenico Roviello ${ }^{1}$, Martina Catalano ${ }^{1}$ (D), Raffaella Santi ${ }^{2}$, Valeria Emma Palmieri ${ }^{1}$, Gianmarco Vannini ${ }^{1}$, \\ Ilaria Camilla Galli ${ }^{2}$, Eleonora Buttitta ${ }^{1}$, Donata Villari ${ }^{3}$, Virginia Rossi ${ }^{4}$ and Gabriella Nesi ${ }^{1, *}$ (i) \\ 1 Department of Health Sciences, University of Florence, 50139 Florence, Italy; \\ giandomenico.roviello@unifi.it (G.R.); martina.catalano@unifi.it (M.C.); \\ valeriaemma.palmieri@unifi.it (V.E.P.); gianmarco.vannini@unifi.it (G.V.); eleonora.buttitta@unifi.it (E.B.) \\ 2 Histopathology and Molecular Diagnostics, Careggi Teaching Hospital, 50139 Florence, Italy; \\ santir@aou-careggi.toscana.it (R.S.); galliic@aou-careggi.toscana.it (I.C.G.) \\ 3 Department of Experimental and Clinical Medicine, University of Florence, 50139 Florence, Italy; \\ donata.villari@unifi.it \\ 4 Clinical Oncology Unit, Careggi Teaching Hospital, 50139 Florence, Italy; rossiv@aou-careggi.toscana.it \\ * Correspondence: gabriella.nesi@unifi.it
}

check for

updates

Citation: Roviello, G.; Catalano, M.; Santi, R.; Palmieri, V.E.; Vannini, G.; Galli, I.C.; Buttitta, E.; Villari, D.;

Rossi, V.; Nesi, G. Immune

Checkpoint Inhibitors in Urothelial Bladder Cancer: State of the Art and Future Perspectives. Cancers 2021, 13, 4411. https://doi.org/10.3390/ cancers13174411

Academic Editor: Mehmet Asim Bilen

Received: 28 July 2021

Accepted: 28 August 2021

Published: 31 August 2021

Publisher's Note: MDPI stays neutral with regard to jurisdictional claims in published maps and institutional affiliations.

Copyright: (c) 2021 by the authors. Licensee MDPI, Basel, Switzerland. This article is an open access article distributed under the terms and conditions of the Creative Commons Attribution (CC BY) license (https:// creativecommons.org/licenses/by/ $4.0 /)$
Simple Summary: Urothelial bladder cancer (BC) is one of the most fatal cancers, with a dismal five-year survival rate of $5 \%$ in patients with metastatic disease. Clinically relevant benefits of immunotherapy in advanced or metastatic bladder cancer have led to Food and Drug Administration (FDA) approval of immune checkpoint inhibitors (ICIs) as second- or first-line therapy in patients unresponsive to or ineligible for standard treatment. The advantage of ICIs is being investigated in various stages of $\mathrm{BC}$, either as monotherapy or in combination with other drugs. In this review we discuss the role of ICIs in BC, highlighting their current clinical application and outlining future therapeutic perspectives.

Abstract: Bladder cancer (BC) is the most common malignancy of the genitourinary tract, with high morbidity and mortality rates. Until recently, the treatment of locally advanced or metastatic urothelial BC was based on the use of chemotherapy alone. Since 2016, five immune checkpoint inhibitors (ICIs) have been approved by the Food and Drug Administration (FDA) in different settings, i.e., first-line, maintenance and second-line treatment, while several trials are still ongoing in the perioperative context. Lately, pembrolizumab, a programmed death-1 (PD-1) inhibitor, has been approved for Bacillus Calmette-Guérin (BCG)-unresponsive high-risk non-muscle invasive bladder cancer (NMIBC), using immunotherapy at an early stage of the disease. This review investigates the current state and future perspectives of immunotherapy in $\mathrm{BC}$, focusing on the rationale and results of combining immunotherapy with other therapeutic strategies.

Keywords: urothelial carcinoma; bladder cancer; PD-1; PD-L1; immune checkpoint blockade; biomarkers

\section{Introduction}

Bladder cancer (BC) is the ninth-most common malignancy worldwide, with 83,730 estimated new cases in the USA in 2021 [1] and the seventh-most common cancer in men [2]. Tobacco smoke appears to be the most common risk factor for $\mathrm{BC}$, accounting for approximately 50\% of cases [3]. Compared with never smokers, BC risk is three-fold higher in former smokers and over six-fold higher in current smokers, steadily increasing with the number of cigarettes and years smoked [4]. Occupational exposure is responsible for 5-6\% of urothelial carcinomas. Among dietary factors, alcohol appears to play a role in the pathogenesis of BC, while the intake of Vitamin D and daily consumption of fruit and vegetables could have a protective effect [5].

At the time of diagnosis, approximately $70 \%$ of urothelial carcinomas are superficial, while $30 \%$ present with muscle infiltration [2]. Treatment of non-muscle invasive bladder 
cancer (NMIBC) involves transurethral resection of the bladder tumor (TURBT) followed by intravesical chemotherapy or immunotherapy. Bacillus Calmette-Guérin (BCG) immunotherapy is the gold standard adjuvant treatment for NMIBC with a high risk of progression and is also recommended for intermediate-risk NMIBC [6].

The standard treatment for nonmetastatic muscle invasive bladder cancer (MIBC) (T2-T4, N0, M0) is neoadjuvant cisplatin-based therapy, succeeded by radical cystectomy (RC) and pelvic lymphadenectomy [7]. Patients undergoing RC for MIBC have a high risk of relapse, especially in cases of $\geq \mathrm{pT} 2$ disease and/or pathological lymph node involvement. Adjuvant cisplatin-based multi-chemotherapy may be considered for patients fulfilling platinum eligibility criteria that include at least one of the following: Eastern Cooperative Oncology Group (ECOG) performance status of 2, creatinine clearance less than $60 \mathrm{~mL} / \mathrm{min}$, grade $\geq 2$ hearing loss, grade $\geq 2$ neuropathy, and/or New York Heart Association Class III heart failure $[8,9]$.

Cisplatin-containing chemotherapy is the preferred first-line treatment also in metastatic disease. The most commonly used regimens in this setting include a combination of gemcitabine and cisplatin (GC), methotrexate, vincristine, adriamycin and cisplatin (MVAC) every four weeks, or dose-dense (dd) MVAC every two weeks. The median overall survival (OS) rates are 13.8 months, 14.8 months, and 15.5 months for GC, MVAC, and ddMVAC regimens, respectively $[10,11]$. Outcome is poor for patients who are unfit for platinum chemotherapy or undergo progression after frontline platinum chemotherapy, however, a major milestone in the metastatic setting was the approval of immune checkpoint inhibitors (ICIs) (Table 1).

Table 1. Currently approved ICIs administered in urothelial bladder carcinoma.

\begin{tabular}{|c|c|c|c|c|c|c|c|}
\hline Trial & Phase & FDA Approval & No. of Patients & ICI Therapy & $\begin{array}{c}\text { Line of } \\
\text { Treatment }\end{array}$ & $\begin{array}{l}\text { Previous } \\
\text { Platinum } \\
\text { Therapy }\end{array}$ & Efficacy Outcomes \\
\hline IMvigor210 [12] & II & May 2016 & 310 & Atezolizumab & Second line & Yes & $\begin{array}{c}\text { mPFS: } 2.1 \mathrm{mo} \\
\text { mOS: } 7.9 \mathrm{mo} \\
\text { ORR: } 18 \%\end{array}$ \\
\hline CheckMate-275 [13] & II & February 2017 & 265 & Nivolumab & Second line & Yes & $\begin{array}{c}\text { mPFS: } 2.0 \mathrm{mo} \\
\text { mOS: } 8.7 \mathrm{mo} \\
\text { ORR: } 20 \%\end{array}$ \\
\hline IMvigor210 [14] & II & April 2017 & 123 & Atezolizumab & $\begin{array}{l}\text { First line PD-L1+ } \\
\text { platinum } \\
\text { ineligible } \\
\text { patients }\end{array}$ & No & $\begin{array}{l}\text { mPFS: } 2.7 \mathrm{mo} \\
\text { mOS: } 15.9 \text { mo } \\
\text { ORR: } 23 \%\end{array}$ \\
\hline JAVELIN Solid Tumor [15] & I & May 2017 & 44 & Avelumab & Second line & Yes & $\begin{array}{l}\text { mPFS: } 11.6 \mathrm{wk} \\
\text { mOS: } 13.7 \mathrm{mo} \\
\text { ORR: } 18.2 \%\end{array}$ \\
\hline Study 1108 [16] & $\mathrm{I} / \mathrm{II}$ & May 2017 & 191 & Durvalumab & Second line & Yes & $\begin{array}{l}\text { mPFS: } 1.5 \text { mo } \\
\text { mOS: } 18.2 \text { mo } \\
\text { ORR: } 18 \%\end{array}$ \\
\hline KEYNOTE-045 [17] & III & May 2017 & 542 & Pembrolizumab & Second line & Yes & $\begin{array}{l}\text { mPFS: } 2.1 \mathrm{mo} \\
\text { mOS: } 10.3 \mathrm{mo} \\
\text { ORR: } 21 \%\end{array}$ \\
\hline KEYNOTE-052 [18] & II & May 2017 & 370 & Pembrolizumab & $\begin{array}{l}\text { First line PD-L1 + } \\
\text { platinum } \\
\text { ineligible } \\
\text { patients }\end{array}$ & No & $\begin{array}{l}\text { mPFS: } 2.2 \text { mo } \\
\text { mOS: } 11.3 \text { mo } \\
\text { ORR: } 29 \%\end{array}$ \\
\hline JAVELIN Bladder 100 [19] & III & June 2020 & 700 & Avelumab & $\begin{array}{l}\text { Maintenance } \\
\text { therapy }\end{array}$ & Yes & $\begin{array}{l}\text { mPFS: } 3.7 \mathrm{mo} \\
\text { mOS: } 21.4 \mathrm{mo}\end{array}$ \\
\hline
\end{tabular}

Immune checkpoint inhibitor (ICI); programmed death ligand 1 (PD-L1); median progression-free survival (mPFS); median overall survival (mOS); objective response rate (ORR); months (mo); weeks (wk).

ICIs are monoclonal antibodies directed against cytotoxic T-lymphocyte-associated antigen 4 (CTLA-4), programmed death 1 (PD-1) receptor and programmed death ligand-1 (PD-L1). CTLA-4 is a membrane receptor acting as a major negative regulator of $\mathrm{T}$ cell responses through interaction with its ligands, CD80 (B7-1) and CD86 (B7-2), expressed on the surface of antigen-presenting cells. PD-1 is a membrane receptor expressed by $\mathrm{T}$ cells, particularly in conditions of chronic antigen exposure, and exerts an inhibitory action 
on lymphocytes by binding to its two ligands, PD-L1 and PD-L2. PD-L1 is expressed on immune cells, such as T cells, B cells, dendritic cells (DCs) and macrophages [20,21], while PD-L2 is expressed mainly on antigen-presenting cells (APCs), including macrophages and myeloid DCs [22,23]. PD-L1 and PD-L2 have differential functions in immune regulatory processes. Indeed, PD-L1 inhibits T cells in peripheral tissues, whereas PD-L2 suppresses immune $\mathrm{T}$ cell activation in lymphoid organs. PD-L2 also inhibits type $2 \mathrm{~T}$-helper $\left(\mathrm{T}_{\mathrm{H}} 2\right)$ lymphocytes, but its role is yet to be fully understood [24,25]. By interrupting the ligand / receptor interactions, the anti-CTLA-4 (ipilimumab, tremelimumab) and anti-PD-1 (nivolumab, pembrolizumab)/anti-PD-L1 (atezolizumab, durvalumab, avelumab) antibodies remove $\mathrm{T}$ cell inhibition, thus favoring antitumor cytotoxic activity [26] (Figure 1). Characterization of immune checkpoints has furthered development of novel immunotherapeutic agents with clinical activity against a variety of solid tumors, including BC.

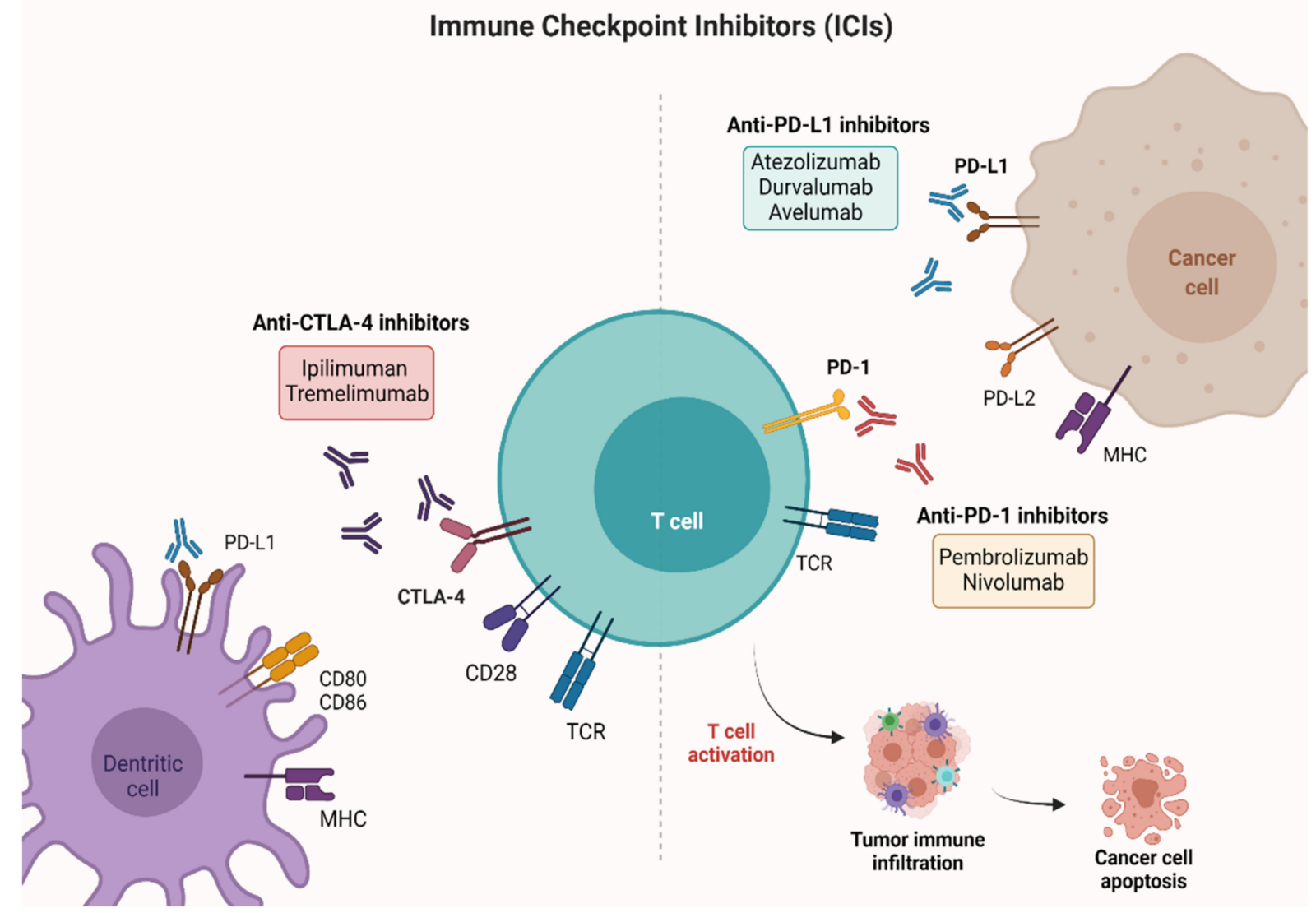

Figure 1. Mechanisms of action of ICIs targeting PD-1, PD-L1, and CTLA-4. PD-1 and CTLA-4 are proteins expressed on activated $\mathrm{T}$ cells. Their binding to the respective ligands presented on the surface of cancer cells leads to $\mathrm{T}$ cell inactivation and prevents tumor cell death. The immune checkpoint blockade ensures the activation of $\mathrm{T}$ cells and favors antitumor activity. Created with BioRender.com (accessed on 26 July 2021). PD-1: Programmed cell death-1; PD-L1: Programmed cell death-ligand 1; CTLA-4: Cytotoxic T-lymphocyte-associated antigen 4.

This article reviews current evidence supporting the use of new checkpoint inhibitors in $\mathrm{BC}$, along with information on biomarkers that may predict response to immunotherapy.

\section{Non-Muscle Invasive Bladder Cancer (NMIBC)}

In approximately $75 \%$ of $\mathrm{BC}$ patients, the disease is confined to the mucosa (stage $\mathrm{Ta}$, carcinoma in situ) or submucosa (stage T1) [27]. Although TURB alone can eradicate TaT1 tumors completely, they commonly recur and can progress to MIBC, thus necessitating the use of adjuvant treatment. In patients with intermediate-risk tumors, one-year full-dose 
BCG treatment or chemotherapy instillations for a maximum of one year is recommended. Conversely, full-dose intravesical BCG for one to three years is indicated in patients with high-risk tumors [28].

Therapeutic options for patients with BCG-unresponsive disease include RC, further intravesical therapy, and systemic therapy. A relatively new addition to the landscape of treatment for BCG-unresponsive NMIBC is pembrolizumab. Initial results of the KEYNOTE-057 phase II trial were reported in February 2019 showing a 38.8\% (40/102) complete response (CR) rate at 3 months. Following the presentation of these data, pembrolizumab received FDA approval in January 2020 for BCG-unresponsive high-risk NMIBC patients, ineligible for, or refusing RC. Key secondary endpoints were duration of response (DOR) and safety. At a median follow-up of 14 months, $72.5 \%$ of patients maintained CR, 25.0\% experienced recurrent NMIBC after CR, but none progressed to MIBC. Treatment-related adverse events (AEs) occurred in $63.1 \%$ of patients, the most frequent being pruritus, fatigue, diarrhea, hypothyroidism, and maculopapular rash. Grade 3-4 AEs occurred in $12.6 \%$ of patients, and one death due to colitis was considered treatmentrelated [29]. Updated data over a 2-year follow-up were submitted at the 2020 American Society of Clinical Oncology (ASCO) Annual Meeting. The median DOR was 16.2 months, and CR rate was $40.6 \%$ with $46.2 \%$ of responses longer than 12 months. The median PFS and OS were not reached [30].

At the 2021 ASCO Genitourinary Cancers Symposium, Balar et al. reported additional results with an extended minimum follow-up of 26.3 months [31]. Among those patients achieving CR, 33.3\% remained in CR for $\geq 18$ months and $23.1 \%$ for $\geq 24$ months as of the data cutoff date. Of the $41.7 \%$ patients undergoing cystectomy after discontinuation of pembrolizumab, 35 (88\%) had no pathological upstaging to MIBC, three $(8 \%)$ had evidence of MIBC, and two (5\%) had no available pathology data. Safety profile remained consistent with what had been previously reported.

Another phase II trial, SWOG S1605, tested atezolizumab in the same setting. The primary outcome was the pathological complete response (pCR) rate at six months, accomplished through mandatory biopsy. A pCR was observed in 30 (41.1\%) patients at 3 months and in $19(26.0 \%)$ at 6 months. The most common AEs were fatigue, pruritus, hypothyroidism, and nausea. Grade 3-5 AEs occurred in $12.3 \%$ of patients, and there was one treatment-related death due to myasthenia gravis [32].

Several clinical trials with other ICI agents, both as monotherapy and as part of a combination therapy, are ongoing and in early-stage BC. Particularly relevant are the POTOMAC trial assessing durvalumab plus BCG in BCG-naïve patients, the KEYNOTE676 study evaluating BCG-associated pembrolizumab in patients with recurrence after induction BCG therapy alone [33], and the NCT03317158 trial establishing the safety of durvalumab as monotherapy and in combination with BCG and external beam radiation therapy (EBRT) in BCG-unresponsive NMIBC patients (Table 2). 
Table 2. Ongoing phase II/III trials with active recruitment on ICIs alone or in combination with chemotherapy in different settings of BC treatment.

\begin{tabular}{|c|c|c|c|c|c|c|c|}
\hline Trial & Phase & Allocation & No. of Patients & Study Populations & Line of Treatment & Experimental Arms & Primary Outcome \\
\hline NCT02736266 & II & $\mathrm{N} / \mathrm{A}$ & 90 & MIBC & $\begin{array}{l}\text { neoadjuvant prior to } \\
\text { chemoradiation }\end{array}$ & Pembrolizumab & $\mathrm{pCR}$ \\
\hline NCT02845323 & II & randomized & 44 & MIBC & neoadjuvant & $\begin{array}{l}\text { Nivolumab + Urelumab vs. } \\
\text { Nivolumab }\end{array}$ & $\begin{array}{l}\text { Immune response } \\
\text { (tumor infiltrating } \\
\text { CD8+ T cell density) }\end{array}$ \\
\hline NCT03520491 & II & not randomized & 45 & $\begin{array}{l}\text { Cisplatin-ineligible patients with } \\
\text { MIBC }\end{array}$ & neoadjuvant & $\begin{array}{l}\text { Nivolumab and Nivolumab + } \\
\text { Ipilimumab }\end{array}$ & $\begin{array}{l}\text { No. of patients who } \\
\text { proceed to RC-PLND }\end{array}$ \\
\hline NCT03472274 & II & randomized & 99 & $\mathrm{BC}$ patients & neoadjuvant & Durvalumab and Tremelimumab & Antitumor activity \\
\hline NCT03732677 & III & randomized & 1050 & MIBC & neoadjuvant/adjuvant & $\begin{array}{l}\text { Durvalumab + Gemcitabine }+ \\
\text { Cisplatin neoadjuvant treatment } \\
\text { followed by Durvalumab alone } \\
\text { for adjuvant treatment }\end{array}$ & EFS \\
\hline NCT04138628 & II & randomized & 282 & $\begin{array}{l}\text { Treatment of } \mathrm{mBC} \text { at the time of } \\
\text { biochemical relapse following RC }\end{array}$ & adjuvant & Atezolizumab & CR \\
\hline NCT03244384 & III & randomized & 739 & Locally advanced and mUC & adjuvant & Pembrolizumab vs. observation & OS, DFS \\
\hline NCT03036098 & III & randomized & 1290 & Unresectable or mUC & 1 st & $\begin{array}{l}\text { Nivolumab + Ipilimumab, or SoC } \\
\text { chemotherapy vs. SoC } \\
\text { Chemotherapy }\end{array}$ & OS, PFS \\
\hline NCT03682068 & III & randomized & 1434 & $\begin{array}{l}\text { Unresectable locally advanced or } \\
\text { mUC }\end{array}$ & 1 st & $\begin{array}{c}\text { Durvalumab + SoC chemotherapy } \\
\text { and Durvalumab }+ \\
\text { Tremelimumab and SoC } \\
\text { Chemotherapy vs. SoC } \\
\text { chemotherapy alone }\end{array}$ & OS \\
\hline NCT03898180 & III & randomized & 694 & Locally advanced or mUC & 1 st & $\begin{array}{l}\text { Pembrolizumab + Lenvatinib vs. } \\
\text { Pembrolizumab + placebo }\end{array}$ & PFS, OS \\
\hline NCT03697850 & II & randomized & 77 & MIBC patients ineligible for RC & maintenance therapy & Atezolizumab & DFS \\
\hline
\end{tabular}

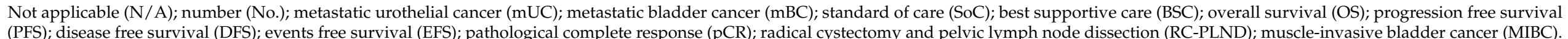




\section{Muscle Invasive Bladder Cancer (MIBC)}

$\mathrm{RC}$ is the treatment of choice for MIBC, nevertheless approximately half of the patients are susceptible to high rates of local and distant relapse, potentially due to undetected occult micrometastases. Neoadjuvant and adjuvant cisplatin-based chemotherapy can be administered, offering modest survival benefit [34,35], however, not all patients are eligible for cisplatin on account of their age or comorbidities [36]. In early phase clinical trials, perioperative ICI strategies have shown encouraging outcomes, although results of phase III randomized controlled trials are eagerly awaited, and sensitive biomarkers are needed to support treatment decision.

\subsection{Neoadjuvant Setting}

Several anti-PD1, anti-PD-L1 and anti-CTLA-4 agents, either individually or in combination, had been investigated as neoadjuvant treatments prior to RC.

In two single-arm phase II trials (PURE-01 and ABACUS), pembrolizumab and atezolizumab as single agents have been tested in the neoadjuvant setting. In the PURE-01 study, patients with MIBC, regardless of cisplatin eligibility, were selected to receive three cycles of pembrolizumab before surgery, switching to chemotherapy (ddMVAC) in case of disease progression. The $\mathrm{pCR}$ rate was $42 \%$ and downstaging to $<\mathrm{pT} 2 \mathrm{~N} 0$ was achieved in $27(54 \%)$ patients [37]. The ABACUS trial assessed the administration of two cycles of atezolizumab in cisplatin-ineligible patients. At a median follow-up of 13.1 months, the pCR rate and 1-year relapse-free survival (RFS) were $31 \%$ and $79 \%$, respectively [38].

Data from a single-arm trial, combining durvalumab with tremelimumab (CTLA-4 inhibitor) in high-risk cisplatin-ineligible patients, were reported by Gao et al. [39]. In this study, the pCR was $49 \%$ and grade 3 immune-related AEs were observed in $17 \%$ of patients.

In another randomized phase II trial, the same ICI combination was compared with neoadjuvant cisplatin-based chemotherapy (GC or ddMVAC) in patients with urothelial MIBC (cT2-T4a N $\leq 1 \mathrm{M} 0$ ), classified as "hot" or "cold" according to tumor immune score (TIS) [40]. Patients with "hot" tumors were randomized to durvalumab plus tremelimumab or standard chemotherapy. The pCR was $36.4 \%$ in the immunotherapy arm vs. $34.8 \%$ in the standard chemotherapy arm (95\% CI, 0.26-3.24). Grade 3-4 AEs were more frequent in the chemotherapy arm.

A recent single-arm feasibility trial enrolled patients, either cisplatin-ineligible or refusing cisplatin-based chemotherapy, to receive nivolumab and the CTLA-4 inhibitor, ipilimumab, with a pCR of $45 \%$ [41]. Grade 3-4 immune-related AEs occurred in 55\% of patients. Contrary to studies with anti-PD-1/PD-L1 monotherapy, CR to ipilimumab plus nivolumab was independent from baseline CD8+ presence or T-effector signatures.

A combination strategy with ICIs and PARP inhibitors was investigated in a phase II clinical trial. This study considered durvalumab plus olaparib in patients with cT2-T4a N0 M0 urothelial carcinoma, demonstrating a pCR rate of $44.5 \%$, and grade $3-4$ AEs in $8.3 \%$ of patients [42]. Evidence suggests that chemotherapy and immunotherapy have synergistic effects, therefore this approach may be associated with improved clinical outcomes.

In a phase $\mathrm{Ib} / \mathrm{II}$ trial, neoadjuvant pembrolizumab combined with GC or gemcitabine in cisplatin-eligible or ineligible patients with cT2-T4a N0 bladder UC has been evaluated. In the cisplatin-eligible cohort, pCR was $44.4 \%$, regardless of baseline PD-L1 score, with an estimated 3-year RFS and OS of $63 \%$ and $82 \%$, respectively. The safety profile documented grade 3-4 cytopenia in $57 \%$ of patients [43]. In the cisplatin-ineligible cohort, the pCR, 1year RFS and OS were $45.2 \%, 67 \%$ and $88.4 \%$, respectively [44]. Nivolumab in combination with GC prior to RC was tested in the BLASST- 1 trial where pCR occurred in $49 \%(20 / 41)$ of cases. The overall rate of grade 3-4 AEs was $24 \%$, the majority being from GC [45].

Perioperative chemoimmunotherapy has been assessed in a phase II trial using four cycles of durvalumab in combination with GC followed by RC and adjuvant durvalumab. No tumor progression was recorded at preoperative restaging with a pCR achieved in 30\% of patients, and a pathological response rate of $50 \%$. Postoperative complications arose in $27 \%$ of cases, and infections were the most common (17\%) [46]. 
Finally, the RETAIN BLADDER trial has been designed to evaluate a risk-adapted approach to the treatment of MIBC following neoadjuvant accelerated methotrexate, vinblastine, doxorubicin, and cisplatin (AMVAC) chemotherapy. Based on the mutational profile and the post-AMVAC biopsy findings, patients are being treated with active surveillance (experimental arm), or standard of care (SoC) intravesicle therapy, chemoradiation or surgery. Achievement of the endpoint (metastasis-free survival at 2 years) would preserve the bladder and improve quality-of-life for a proportion of patients (NCT02710734).

Overall, a combination of durable clinical activity and tolerability has expanded the utility of this group of drugs to early-stage disease, either as monotherapy or in combination with other agents. Given their favorable toxicity profile, ICIs may also provide benefits to a larger patient population, including those with impaired renal function owing to disease status and comorbidities. However, optimal timing between immunotherapy and surgery, number of cycles of ICIs before surgery, and continuation of treatment after RC must be clarified. Validation of predictive biomarkers to identify which patients to treat is a compelling clinical need.

\subsection{Adjuvant Setting}

The addition of systemic therapy following surgery, or adjuvant therapy, is regularly used in many solid tumors, but is not standard management in $\mathrm{BC}$, largely owing to lack of clinical data and cisplatin-based chemotherapy ineligibility [47]. The low rate of treatment-related toxicities associated with ICIs make these agents an attractive therapeutic option in the postoperative setting.

The role of adjuvant ICIs in urothelial cancer (UC) was evaluated in three phase III clinical trials. Patients at high risk of recurrence were defined as those who had received neoadjuvant cisplatin-based chemotherapy with at least pathological T2 or node-positive disease, or those who had not received neoadjuvant chemotherapy with at least pathological T3 disease and were ineligible for cisplatin-based chemotherapy. The experimental arms consisted of atezolizumab, nivolumab or pembrolizumab given as single agents for up to 12 months. The IMvigor010 trial failed to meet its primary endpoint of improved disease-free survival (DFS) in the atezolizumab group recording, at a median follow-up of 21.9 months, a median DFS of 19.4 months vs. 16.6 months in the observation arm (HR, $0.89 ; 95 \%$ CI, 0.74-1.08; $p=0.24$ ). Although relatively immature, these data do not support the use of atezolizumab in the adjuvant setting [48]. Conversely, the interim analysis of CheckMate-274, presented at the 2021 ASCO Genitourinary Cancers Symposium, showed a median DFS in all randomized patients of 21.0 months in the nivolumab arm vs. 10.9 months in the placebo arm (HR, $0.70 ; p=0.0006)$ [49]. Finally, pembrolizumab is still being tested in a phase III randomized clinical trial, enrolling and randomizing patients to receive immunotherapy or observation alone in the adjuvant setting (NCT03244384).

\section{Advanced or Metastatic Bladder Cancer}

\subsection{First-Line Therapy}

The first-line treatment of metastatic urothelial cancer (mUC) is usually cisplatin-based combination chemotherapy [50-52]. However, despite high initial response rates, nearly all patients progress and die from $\mathrm{BC}$. In addition, a subgroup of patients who are candidates for combination chemotherapy are unable to receive cisplatin due to renal dysfunction, neuropathy, severe hearing loss or heart failure.

The efficacy of carboplatin-based therapy was evaluated in the EORTC trial 30986, where 238 chemotherapy-naïve patients with impaired renal function (glomerular filtration rate $<60$ but $>30 \mathrm{~mL} / \mathrm{min}$ ), and/or an Eastern Cooperative Oncology Group (ECOG) PS $\geq 2$, were randomly assigned to treatment with carboplatin and gemcitabine, or methotrexate, carboplatin and vinblastine (MCAVI) [53]. The combination of gemcitabine and carboplatin proved to be as effective as MCAVI, with a better toxicity profile, therefore supporting use in patients with impaired renal function or a poor ECOG -PS $\geq 2$ who are otherwise candidates for combination chemotherapy. 
In recent years, ICIs have become an important therapeutic strategy in many solid tumors [54-59]. High levels of PD-L1 expression have been found in mUC with poor outcome. ICIs can be used to treat patients who are ineligible for any platinum-based (cisplatin or carboplatin) chemotherapy, regardless of PD-L1 expression status.

The efficacy of pembrolizumab as first-line therapy in mUC was evaluated in the phase II KEYNOTE-052 study, where 370 patients with advanced UC ineligible for a cisplatinbased regimen were given pembrolizumab at $200 \mathrm{mg}$ every 21 days for up to 24 months [60]. After a minimum follow-up of two years, the objective response rate (ORR) was $29 \%$ for the entire cohort, comprising 9\% CR and 20\% partial response (PR). The median DOR and OS was 30 and 11.3 months, respectively [18]. The ORR was higher in patients with PD-L1 expression $>10 \%$, but responses were also observed in those with PD-L1 expression $<10 \%$.

The phase III KEYNOTE-361 trial is a randomized study comparing (1:1:1) pembrolizumab + / - chemotherapy (cisplatin or carboplatin plus gemcitabine) in 1010 patients with treatment-naïve unresectable or metastatic BC [61]. The median PFS and median OS were 8.3 and 17 months, respectively, for the combination therapy vs. 7.1 and 14.3 months for chemotherapy alone. This study failed to meet the co-primary endpoints of PFS and OS.

The DANUBE trial, a phase III study, compared durvalumab + / - tremelimumab vs. gold standard chemotherapy in patients with untreated unresectable locally advanced or metastatic BC [62]. This study enrolled 1032 patients distributed randomly (1:1:1) to receive durvalumab alone, durvalumab plus tremelimumab or chemotherapy. The two primary endpoints were OS between the groups treated with durvalumab alone and standard chemotherapy in the population with high PD-L1 expression, and OS between the durvalumab plus tremelimumab and SoC in the intention to treat (ITT) population. This trial failed to achieve either primary endpoint. After a median follow-up of 41.2 months, median OS in the durvalumab group was 14.4 vs. 12.1 months in the chemotherapy arm, while in the ITT population, median OS was 15.1 months in the experimental arm and 12.1 months in the chemotherapy group. The AEs grade 3 or 4 were far more severe and frequent in patients receiving chemotherapy $(60 \%)$ than in patients treated with durvalumab (14\%) or durvalumab plus tremelimumab (27\%) [62].

The efficacy of durvalumab is also being investigated in the NILE trial, a multicenter phase III study of 1215 patients with locally advanced or metastatic BC, who were randomized to receive durvalumab + / - tremelimumab with platinum-based chemotherapy (1:1:1). The original co-primary endpoints were PFS and OS for durvalumab plus chemotherapy vs. chemotherapy in the ITT population [63].

Atezolizumab was approved by the FDA based on the results of the IMvigor210 trial, testing atezolizumab as first-line therapy in patients with cisplatin-ineligible mUC [14]. PD-L1 expression on tumor-infiltrating immune cells (ICs) was assessed by immunohistochemistry, with categories defined by percentage of positive cells: IC0 $(<1 \%)$, IC1 $(\geq 1 \%$ but $<5 \%$ ), and IC2/3 ( $\geq 5 \%$ ) [12]. After a median follow-up of 17 months, OR was observed in $23 \%$ (95\% CI, $16-31$ ) of patients: $28 \%$ in IC2/3, $24 \%$ in IC $1 / 2 / 3,21 \%$ in IC1, and $21 \%$ in IC0 patients. Median DOR was not reached, and 19 of 27 responses were ongoing at the time of analysis. Median PFS was 2.7 months (95\% CI 2.1-4.2) in all patients, 4.1 months in IC2 $/ 3$ patients, 2.1 months in IC1 patients, and 2.6 months in IC0 patients. Median OS was 15.9 months ( $95 \%$ CI, 10.4 to not estimable) for the whole cohort, 12.3 months for IC $2 / 3$ patients, and 19.1 months in IC0/1 patients.

The most important trial investigating atezolizumab as first-line therapy is the IMvigor130 study, a placebo-controlled phase III trial in patients with untreated locally advanced or metastatic BC. It consisted of 1213 patients randomized into three groups: atezolizumab plus platinum-based chemotherapy, atezolizumab as monotherapy, and platinum-based chemotherapy plus placebo. After a median follow-up of 11.8 months, the median PFS was 8.2 months in the atezolizumab plus chemotherapy group vs. 6.3 months in the placebo plus chemotherapy group (HR, $0.82 ; 95 \% \mathrm{CI}, 0.70-0.96 ; p=0.007)$ [64]. 


\subsection{Maintenance Therapy}

In mUC patients, maintenance therapy with ICIs can be administered after an objective response (OR), or disease stability, to platinum-based chemotherapy regardless of PD-L1 tumor status.

The JAVELIN Bladder 100 study is a randomized phase III trial enrolling 700 patients with locally advanced or metastatic BC who showed OR, CR or partial response (PR), or else stable disease (SD), after four to six cycles of platinum-containing chemotherapy [19]. The patients were randomly assigned to either maintenance avelumab plus best supportive care (BSC) or BSC alone (control). OS at 1 year reached $71.3 \%$ in the avelumab group and $58.4 \%$ in the control group $(p=0.001)$. Avelumab also significantly extended OS in the PD-L1-positive population, with a 1-year OS of 79.1\% in the avelumab group and $60.4 \%$ in the control group $(p<0.001)$. AEs from any cause reached $98.0 \%$ in the avelumab group and $77.7 \%$ in the control group, with grade 3 or higher AEs occurring in $47.4 \%$ and $25.2 \%$ of patients, respectively. Based on these results, the US FDA approved avelumab for maintenance therapy in patients with locally advanced or metastatic $B C$, not progressing on initial platinum-based chemotherapy.

Hoosier Cancer Research Network's GU14-182 is a phase II trial enrolling patients randomly assigned to receive maintenance placebo or pembrolizumab after platinumbased chemotherapy. Most patients had visceral metastatic disease. The primary endpoint was to define PFS in accordance with immune-related response evaluation criteria in solid tumors (RECIST). PFS was significantly longer with pembrolizumab than with the placebo (5.4 months and 3.0 months, respectively). Median OS was 22 months (95\% CI, 12.9 months to not reached) with pembrolizumab, and 18.7 months (95\% CI, 11.4 months to not reached) with the placebo. No significant interaction was found between PD-L1 combined positive score (CPS) $\geq 10$ and treatment arm for PFS and OS [65].

The role of other agents has not yet been established in the maintenance setting. Indeed, vinflunine, a third-generation bifluorinated semi-synthetic vinca alkaloid, has shown progression-free, but not OS benefit in randomized phase II trials [66].

\subsection{Second-Line Therapy and Beyond}

Over the last few years, two PD-1 (nivolumab and pembrolizumab) and three PD-L1 (atezolizumab, durvalumab and avelumab) inhibitors have been approved in the metastatic setting [67].

Based on the KEYNOTE-045 study, pembrolizumab was approved by the FDA in May 2017 for patients with locally advanced or metastatic disease which recurred or progressed after platinum-containing chemotherapy [17]. Pembrolizumab was associated with significantly longer OS (10.3 months vs. 7.4 months in the chemotherapy group), with fewer treatment-related AEs.

Following the results of the phase II trial IMvigor210, atezolizumab was approved by the FDA in May 2016 for the treatment of locally advanced or metastatic BC after failure of platinum-based chemotherapy [12]. In this study, 310 patients with advanced disease were enrolled to receive atezolizumab. At a median follow-up of 11.7 months, the ORR was $15 \%$, with a manageable safety profile of the drug. Increased levels of PD-L1 expression on immune cells ( $>5 \%$ of tumor-infiltrating lymphocytes expressing PD-L1 determined by immunohistochemistry) were associated with increased response. Grade 3-4 treatmentrelated AEs occurred in $50(16 \%)$ patients while grade 3-4 immune-mediated AEs in 15 $(5 \%)$, with prevalence of pneumonitis, increased aspartate aminotransferase (AST) and alanine aminotransferase (ALT), rash, and dyspnea. No treatment-related deaths occurred during the study.

Safety and efficacy of atezolizumab vs. chemotherapy (docetaxel, paclitaxel or vinflunine) were assessed in the phase III IMvigor211 trial, where 931 patients were assigned and received atezolizumab or chemotherapy. Atezolizumab was not associated with significantly longer OS than chemotherapy, but its safety profile was more favorable. Grade 3-4 
treatment-related AEs were lower in the atezolizumab group (20\%) than in the chemotherapy group (43\%) [68].

In mUC, safety and antitumor activity of nivolumab were first recorded in the nonrandomized CheckMate-032 study that assessed the efficacy of nivolumab, alone or in combination with ipilimumab, in several advanced tumor settings. OR was achieved in 19 of $78(24.4 \%)$ mUC patients of the nivolumab monotherapy group $(95 \% \mathrm{CI}, 15.3-35.4)$ with a manageable safety profile [69]. In this study, patient response did not appear to be influenced by PD-L1 expression on tumor cells.

The single-arm, phase II CheckMate-275 study evaluated nivolumab in 270 patients with locally advanced, surgically unresectable or metastatic disease, which had progressed despite previous platinum-containing therapy [13]. Median follow-up for OS was 7 months (interquartile range, 2.96-8.77) and confirmed OR was achieved in 52 of 265 patients, regardless of PD-L1 expression (95\% CI, 15.0-24.9). Grade 3-4 treatment-related AEs occurred in $48(18 \%)$ patients, usually grade 3 fatigue and diarrhea. Three deaths (pneumonitis, acute respiratory failure, and cardiovascular failure) were attributed to treatment. The favorable results of this study led to accelerated FDA approval of nivolumab for treatment of patients with locally advanced or mUC who have disease progression during or following platinum-based chemotherapy.

In a phase I/II multicenter, open-label study, durvalumab administered every 2 weeks showed favorable clinical activity in platinum-refractory UC patients [16]. The ORR was $17.8 \%$ (95\% CI, 12.7-24.0), including 7 CR. Responses occurred early (median time to response, 1.41 months), were durable (median DOR not reached), and did not differ by PD-L1 expression status. Grade 3-4 treatment-related AEs were seen in 13 patients $(6.8 \%)$ and grade $3-4$ immune-mediated AEs in 4 patients (2.1\%).

The JAVELIN Solid Tumor study, a phase Ib single-arm trial, assessed the safety and efficacy of avelumab in patients with refractory mUC [15]. Forty-four patients were treated with avelumab (10 mg/kg every 2 weeks) and followed for a median of 16.5 months. Median PFS was 11.6 weeks (95\% CI, 6.1 to 17.4 weeks) and median OS 13.7 months ( $95 \%$ CI, 8.5 months to not estimable), with a 12 -month OS rate of $54.3 \%$. The most frequent treatment-related AEs of any grade were fatigue/asthenia (31.8\%), infusionrelated reaction $(20.5 \%)$, and nausea $(11.4 \%)$. Grade $3-4$ asthenia and increase of AST and creatine phosphokinase (CPK) occurred in $3(6.8 \%)$ patients.

\section{Biochemical and Clinical Predictors of Response to Immune Checkpoint Inhibitors (ICIs)}

Only a subset of mUC patients undergoing ICI therapy develop a concrete and lasting response. Indeed, some patients receive little or no benefit from immunotherapy. The mechanisms underlying the marked variability of response to ICIs are not yet fully known and it is crucial to identify predictive biomarkers as well as resistance mechanisms in ICI non-responders. Currently FDA-approved biomarkers are PD-L1 expression and microsatellite instability-high (MSI-H)/mismatch repair deficiency (dMMR) for tumor agnostic therapy. Other emerging predictive biomarkers include tumor mutational load (TMB), gene expression profiles (GEP), the cancer genome atlas (TCGA) profile, and tumor infiltrating lymphocytes (TIL) [70].

\section{1. $P D-L 1$}

In mUC, a satisfactory response rate was observed in patients with high PD-L1 expression treated in second-line with pembrolizumab and durvalumab, or in first-line with avelumab. However, no correlation was found between PD-L1 expression and OS in patients receiving second-line nivolumab and pembrolizumab [13,15-17,66,68-73]. PDL1 expression detected by immunohistochemistry does not necessarily correlate with response to treatment. Some studies have shown that the negative predictive value of the test is poor and does not allow clinical discrimination between responders and nonresponders $[16,60,73]$. Indeed, there is presently no standardized method and definition of PD-L1 positivity. Although immunohistochemistry is used as a reference test, staining 
methods and scoring systems vary considerably, leading to conflicting results. Lastly, heterogeneity in PD-L1 expression poses a further problem.

\subsection{Tumor Mutational Burden (TMB)}

High TMB is a leading candidate biomarker of immunotherapy response in various malignancies. TMB is defined as the number of somatic mutations (e.g., single-nucleotide variant, nonsense, missense, and splice site mutations) per megabase of interrogated genomic sequence harbored by cancer cells. Metastatic BC is characterized by high rates of somatic mutations, particularly in the Lund genomically unstable (LGU) group and TCGA cluster II group.

In the IMvigor210 trial, response to atezolizumab was significantly higher in TCGA cluster II patients than in other subtypes [14,74-76]. Indeed, increasing the number of mutant proteins would generate antigenic peptides, thereby enhancing immunogenicity [77]. A significant association between TMB and response to immunotherapeutic drugs has been observed in several tumor types, including mUC $[14,17]$. Recently, the CheckMate275 study showed improved ORR (31.9\% vs. $17.4 \%, p=0.002)$ and PFS (3.02 months vs. 1.87 months) in patients with high TMB [78]. However, the clinical application and predictive power of this biomarker need to be further elucidated, and a way to discriminate responsive from nonresponsive patients has yet to be codified [79]. Low TMB does not necessarily correlate with lack of immunotherapy response, nor does high TMB always identify those patients most likely to benefit from immune checkpoint blockade [80].

\subsection{Microsatellite Instability (MSI)}

Mutations in genes involved in the MMR pathway cause defective DNA damage repair, which can be a predictive biomarker for ICI response [81]. Tumors with dMMR will also have additional mutations in non-MSI regions throughout the genome, and consequently more neoantigens than those with intact MMR, making antitumor immune response more effective and response to ICIs more likely. MSI/dMMR is therefore a cogent predictive biomarker for immunotherapy in such tumors, regardless of histological origin. MMR mutations have been associated with higher response rates to anti-PD-1 and anti-PDL1 agents, and longer survival than in patients with high TMB alone [70]. Contrariwise, the IMvigor210 study showed better response in patients with high TMB than with dMMR [82]. This apparent divergence in results could be explained by the lack of standardized data and the mutation variability of the genes involved in MMR.

\subsection{Gene Expression Profiles (GEP)}

Gene expression profiling has been proven useful as a predictive biomarker of response to ICI treatment [83-86]. Of the sequenced genes, interferon-gamma (IFN- $\gamma$ ) expression may lead to consistently better prediction of ICI therapy outcomes. IFN- $\gamma$ is a key cytokine for adaptive and innate anticancer mechanisms of the immune system, although it is also involved in immune evasion strategies of tumor cells. In the KEYNOTE-052 trial, which evaluated the efficacy of first-line pembrolizumab in cisplatin-ineligible advanced UC, GEP score showed a significant correlation with ORR $(p<0.0001)$ and could offer improved predictive performance to ICI response [87].

Recently, Tang et al. identified four immunotypes of $\mathrm{BC}$, referred to as $\mathrm{C} 1-\mathrm{C} 4$, based on gene expression profiles. $\mathrm{C} 2$ had the highest degree of immune cell infiltration, while C4 exhibited a "desert"-like phenotype deprived of CD8+ cells. They demonstrated that the $\mathrm{C} 2$ subtype showed better OS and was more sensitive to anti-PD-1 treatment than other subtypes [88].

\subsection{Tumor Infiltrating Cytotoxic T Lymphocytes}

High infiltration of $\mathrm{T}$ lymphocytes in the tumor microenvironment has been correlated to a higher response rate with increased DFS and OS. Although there is no conclusive evidence, a retrospective analysis of 31 patients with muscle-invasive UC found that 
patients with more than eight CD8+ TILs had a longer median survival than patients with less than eight CD8+ cells [89]. Some clinical trials, e.g., IMvigor210 and PCD4989g, have attempted to outline a preliminary prognostic profile of response to treatment in mUC [90]. It has been observed that the absence of visceral metastases and neutrophil-tolymphocyte ratio (NLR) lower than 5 are associated with clinical benefits. Neutrophilia and a higher concentration of neutrophils within the tumor could impair $\mathrm{T}$ cell function through overexpression of PD-L1 [91]. The assessment of TILs in routine pathology reports for advanced UC patients may be helpful but warrants further research as a standardized and validated biomarker.

\section{Combination Strategies with Immune Checkpoint Inhibitors (ICIs)}

Chemotherapy remains a critical component of the treatment armamentarium of UC and is unlikely to be replaced by ICIs or new target therapies in the immediate future. However, chemotherapeutic agents may have a synergistic effect and amplify the activation of CD8+ T cells achieved with ICIs.

Immunosuppressive cells, such as myeloid-derived suppressor cells (MDSCs), can induce immune tolerance, impeding the recognition and destruction of BC cells [92]. MDSCs are recruited and activated by tumor-derived factors and directly promote tumor growth, neovascularization and metastasis. Migrating into the tumor microenvironment, MDSCs also inhibit the antitumor reactivity of T lymphocytes and natural killer (NK) cells. Several chemotherapeutic drugs have been reported to regulate the immune environment of cancers, among which cisplatin can selectively deplete granulocytic-MDSCs (G-MDSCs), thus maintaining the function of CD8+ T cells against cancer [93].

\subsection{ICIs with Chemotherapy}

Data from the IMvigor210 trial suggest that chemotherapy can modulate PD-L1 expression in the tumor microenvironment. High PD-L1 expression was associated with improved ORR in patients previously treated with chemotherapy (cohort 2), but not in patients who had not received chemotherapy (cohort 1) [12]. A retrospective study investigating the impact of neoadjuvant chemotherapy on PD-L1 expression in urothelial carcinoma showed that PD-L1 levels increased following chemotherapy [94].

With regard to PFS, the IMvigor130 trial showed the advantage of combined chemoimmunotherapy (atezolizumab) over chemotherapy alone (8.2 months vs. 6.3 months; $\mathrm{HR}, 0.82 ; 95 \% \mathrm{CI}, 0.70-0.96 ; p=0.007)$, while no statistically significant benefit on OS was seen at the interim analysis after a median follow-up of 11.8 months [64]. Similarly, the final analysis of the KEYNOTE-361 study suggests that the addition of pembrolizumab to first-line platinum-based chemotherapy does not yield survival benefits in patients with advanced UC [61].

\subsection{ICI Combination}

The combination of PD-1/PD-L1 inhibitors and anti-CTL-4 antibodies seems to increase antitumor activity [62]. In the CheckMate-032 phase I/II trial, patients who progressed after platinum-based chemotherapy received either nivolumab or one of two nivolumab plus ipilimumab combination regimens [95]. Patients were treated with nivolumab $3 \mathrm{mg} / \mathrm{kg}$ (NIVO3) every 2 weeks or nivolumab $3 \mathrm{mg} / \mathrm{kg}+$ ipilimumab $1 \mathrm{mg} / \mathrm{kg}$ (NIVO3 + IPI1) or nivolumab $1 \mathrm{mg} / \mathrm{kg}+$ ipilimumab $3 \mathrm{mg} / \mathrm{kg}$ (NIVO1 + IPI3) every 3 weeks for 4 cycles followed by nivolumab $3 \mathrm{mg} / \mathrm{kg}$ every 2 weeks. The ORR was $25.6 \%$, $26.9 \%$, and $38.0 \%$ in the NIVO3, NIVO3 + IPI1, and NIVO1 + IPI3 arms, respectively. Grade 3 or 4 treatment-related AEs occurred in $21(26.9 \%), 32(30.8 \%)$, and $36(39.1 \%)$ patients receiving NIVO3, NIVO3 + IPI1, and NIVO1 + IPI3, respectively. These findings not only encourage further investigation into NIVO1 + IPI3 in $\mathrm{mUC}$, they also demonstrate the added benefit of immunotherapy combinations in this disease [95]. 


\subsection{ICIs with Target Therapies}

Several studies on ICIs combined with target therapies are currently ongoing. The phase $\mathrm{Ib} / \mathrm{II}$ clinical trial FORT-2 evaluates the use of rogaratinib, an oral pan-FGFR1-4 inhibitor, in combination with atezolizumab in patients with first-line cisplatin-ineligible, FGFR-positive, advanced/mUC. Preliminary results, presented at the 2020 ASCO meeting, showed an ORR of $39 \%$ and a disease control (DC) rate of $65 \%$ [96].

Clinical activity of vofatamab, an antibody against FGFR3 blocking activation of both the wild-type and genetically activated receptor, was assessed in combination with pembrolizumab in the phase Ib/II FIERCE-22 clinical trial [97]. ORR was 32\%, however, further studies are mandatory to better elucidate the synergy between FGFR inhibition and checkpoint blockade immunotherapy.

\subsection{ICI with Antiangiogenic Drugs}

Angiogenesis is known to play a pivotal role in the natural history of various malignancies, contributing to the pathogenesis and progression [98]. ICIs plus antiangiogenic agents have been confirmed to improve clinical outcomes in metastatic kidney cancer and are also currently being evaluated in UC.

Final results from a phase I trial and expansion cohorts of cabozantinib and nivolumab alone or with ipilimumab for metastatic genitourinary tumors were presented at the 2021 ASCO Genitourinary Cancers Symposium. The ORR for UC was $42.4 \%$ with $21.2 \%$ of CR, and median OS was 24.9 months (95\% CI, 11.8-41.6) [99]. These regimens also demonstrated manageable safety. Grade 3-4 treatment-related AEs, including fatigue, diarrhea, and hypertension, occurred in $75 \%$ and $87 \%$ of patients treated with cabozantinib and nivolumab (CaboNivo) or CaboNivo plus ipilimumab (CaboNivoIpi), respectively. Grade 3-4 immune-related AEs were only seen in the triplet, and encompassed hepatitis $(13 \%)$ and colitis $(7 \%)$ [100].

In the phase Ia/b JVDF trial enrolling patients with previously treated advanced UC, the combination of pembrolizumab with ramucirumab, an IgG1 monoclonal antibody that binds to the extracellular domain of vascular endothelial growth factor receptor-2 (VEGFR2), achieved confirmed OR in 3 (13\%) of 24 patients [101]. Nevertheless, this approach needs to be investigated in future trials, either with or without chemotherapy.

\subsection{ICIs with Antibody-Drug Conjugates}

Antibody-drug conjugates (ADCs) comprise a tumor-specific monoclonal antibody conjugated to a potent cytotoxin via a chemical linker [102]. The chemotherapeutic agent is only released within those cells expressing the protein target after internalization of the ADC and lysosomal cleavage.

Enfortumab vedotin (ASG-22ME) is an ADC composed of an anti-nectin-4 monoclonal antibody attached to monomethyl auristatin E, a microtubule-disrupting agent. This agent targets nectin-4, a cell adhesion molecule highly expressed in numerous cancers, including UC [103]. EV-201 is a global, phase II, single-arm study of enfortumab vedotin for patients with locally advanced or metastatic BC, previously treated with platinum-containing chemotherapy and PD-1/L1 inhibitors. Enfortumab vedotin was administered to $125 \mathrm{mUC}$ patients with an ORR of $44 \%$ (95\% CI, 35.1-53.2), including $12 \%$ CR. The most common treatment-related AEs were fatigue (50\%), peripheral neuropathy (50\%), alopecia (49\%), rash $(48 \%)$, decreased appetite (44\%), and dysgeusia (40\%) [71]. Safety and anti-tumor activity of enfortumab vedotin, alone or in combination with pembrolizumab and/or chemotherapy, are being studied in the first-line setting (NCT03288545). Preliminary data from the 2020 ASCO Annual Meeting showed encouraging and durable activity of pembrolizumab plus enfortumab vedotin with an ORR of $73.3 \%$ and median PFS of 12.3 months [104]. Moreover, a tolerable and stable safety profile was reported in cisplatin-ineligible patients. Based on these results, in February 2020, the FDA granted breakthrough therapy designation for enfortumab vedotin combined with pembrolizumab as first-line treatment in cisplatin-ineligible patients with unresectable locally advanced or 
mUC. Updated data with 24.9-month median follow-up were presented at the 2021 ASCO Annual Meeting. Median DOR was 25.6 months and OS rate 56.3\% (95\% CI, 39.8-69.9), with a manageable safety profile [105].

Sacituzumab govitecan (SG) is an ADC directed against trophoblast cell surface antigen 2 (Trop-2), a transmembrane glycoprotein expressed on the surface of most epithelial cancer cells. SG activity is under investigation in $\mathrm{mUC}$ patients progressing after prior platinum and ICI therapies, and preliminary results are encouraging [106]. In 113 patients who received SG, the ORR was $27 \%$, and median DOR was 7.2 months, with median PFS and OS of 5.4 and 10.9 months, respectively.

\section{Conclusions}

The introduction of ICIs has dramatically changed the treatment paradigm for locally advanced or metastatic BC. Since 2016, ICIs have shown clinical benefits with a significant impact on OS and a durable tumor control in first-line therapy or upon relapse after standard treatments. More recently, immune checkpoint blockade has also proven beneficial in early-stage disease. New combinatorial strategies are under investigation to improve UC management, while further biomarker development is required to guide treatment in individual patients.

Author Contributions: Conceptualization, G.N. and G.R.; Data Curation, M.C., R.S., V.E.P., G.V., I.C.G., E.B. and D.V.; Writing, M.C., V.R., V.E.P., G.V. and E.B.; Review \& Editing, G.N. and G.R.; Visualization, G.R.; Supervision, G.N. All authors have read and agreed to the published version of the manuscript.

Funding: This research received no external funding.

Conflicts of Interest: The authors declare no conflict of interest.

\section{References}

1. Siegel, R.L.; Miller, K.D.; Fuchs, H.E.; Jemal, A. Cancer Statistics, 2021. CA Cancer J. Clin. 2021, 71, 7-33. [CrossRef]

2. Antoni, S.; Ferlay, J.; Soerjomataram, I.; Znaor, A.; Jemal, A.; Bray, F. Bladder Cancer Incidence and Mortality: A Global Overview and Recent Trends. Eur. Urol. 2017, 71, 96-108. [CrossRef] [PubMed]

3. Cumberbatch, M.G.; Rota, M.; Catto, J.W.; La Vecchia, C. The Role of Tobacco Smoke in Bladder and Kidney Carcinogenesis: A Comparison of Exposures and Meta-analysis of Incidence and Mortality Risks. Eur. Urol. 2016, 70, 458-466. [CrossRef]

4. Polesel, J.; Bosetti, C.; di Maso, M.; Montella, M.; Libra, M.; Garbeglio, A.; Zucchetto, A.; Turati, F.; Talamini, R.; La Vecchia, C.; et al. Duration and intensity of tobacco smoking and the risk of papillary and non-papillary transitional cell carcinoma of the bladder. Cancer Causes Control 2014, 25, 1151-1158. [CrossRef]

5. Cumberbatch, M.G.; Jubber, I.; Black, P.C.; Esperto, F.; Figueroa, J.D.; Kamat, A.M.; Kiemeney, L.; Lotan, Y.; Pang, K.; Silverman, D.T.; et al. Epidemiology of Bladder Cancer: A Systematic Review and Contemporary Update of Risk Factors in 2018. Eur. Urol. 2018, 74, 784-795. [CrossRef] [PubMed]

6. Babjuk, M.; Burger, M.; Compérat, E.M.; Gontero, P.; Mostafid, A.H.; Palou, J.; van Rhijn, B.W.G.; Rouprêt, M.; Shariat, S.F.; Sylvester, R.; et al. European Association of Urology guidelines on non-muscle-invasive bladder cancer (TaT1 and carcinoma in situ) -2019 Update. Eur. Urol. 2019, 76, 639-657. [CrossRef]

7. Ghandour, R.; Singla, N.; Lotan, Y. Treatment options and outcomes in nonmetastatic muscle invasive bladder cancer. Trends Cancer 2019, 5, 426-439. [CrossRef] [PubMed]

8. Kim, D.K.; Lee, J.Y.; Jung, J.H.; Hah, Y.S.; Cho, K.S. Role of adjuvant cisplatin-based chemotherapy following radical cystectomy in locally advanced muscle-invasive bladder cancer: Systematic review and meta-analysis of randomized trials. Investig. Clin. Urol. 2019, 60, 64-74. [CrossRef] [PubMed]

9. Galsky, M.D.; Hahn, N.M.; Rosenberg, J.; Sonpavde, G.; Hutson, T.; Oh, W.K.; Dreicer, R.; Vogelzang, N.; Sternberg, C.N.; Bajorin, D.F.; et al. Treatment of patients with metastatic urothelial cancer "unfit" for cisplatin-based chemotherapy. J. Clin. Oncol. 2011, 29, 2432-2438. [CrossRef]

10. Von der Maase, H.; Hansen, S.W.; Roberts, J.T.; Dogliotti, L.; Oliver, T.; Moore, M.J.; Bodrogi, I.; Albers, P.; Knuth, A.; Lippert, C.M.; et al. Gemcitabine and cisplatin versus methotrexate, vinblastine, doxorubicin, and cisplatin in advanced or metastatic bladder cancer: Results of a large, randomized, multinational, multicenter, phase III study. J. Clin. Oncol. 2000, 18, 3068-3077. [CrossRef] 
11. Sternberg, C.N.; de Mulder, P.H.; Schornagel, J.H.; Théodore, C.; Fossa, S.D.; van Oosterom, A.T.; Witjes, F.; Spina, M.; van Groeningen, C.J.; de Balincourt, C.; et al. Randomized phase III trial of high-dose-intensity methotrexate, vinblastine, doxorubicin, and cisplatin (MVAC) chemotherapy and recombinant human granulocyte colony-stimulating factor versus classic MVAC in advanced urothelial tract tumors: European Organization for Research and Treatment of Cancer Protocol no. 30924. J. Clin.Oncol. 2001, 19, 2638-2646. [CrossRef]

12. Rosenberg, J.E.; Hoffman-Censits, J.; Powles, T.; van der Heijden, M.S.; Balar, A.V.; Necchi, A.; Dawson, N.; O’Donnell, P.H.; Balmanoukian, A.; Loriot, Y.; et al. Atezolizumab in patients with locally advanced and metastatic urothelial carcinoma who have progressed following treatment with platinum-based chemotherapy: A single-arm, multicentre, phase 2 trial. Lancet 2016, 387, 1909-1920. [CrossRef]

13. Sharma, P.; Retz, M.; Siefker-Radtke, A.; Baron, A.; Necchi, A.; Bedke, J.; Plimack, E.R.; Vaena, D.; Grimm, M.O.; Bracarda, S.; et al. Nivolumab in metastatic urothelial carcinoma after platinum therapy (CheckMate 275): A multicentre, single-arm, phase 2 trial. Lancet Oncol. 2017, 18, 312-322. [CrossRef]

14. Balar, A.V.; Galsky, M.D.; Rosenberg, J.E.; Powles, T.; Petrylak, D.P.; Bellmunt, J.; Loriot, Y.; Necchi, A.; Hoffman-Censits, J.; Perez-Gracia, J.L.; et al. IMvigor210 Study Group. Atezolizumab as first-line treatment in cisplatin-ineligible patients with locally advanced and metastatic urothelial carcinoma: A single-arm, multicentre, phase 2 trial. Lancet 2017, 389, 67-76. [CrossRef]

15. Apolo, A.B.; Infante, J.R.; Balmanoukian, A.; Patel, M.R.; Wang, D.; Kelly, K.; Mega, A.E.; Britten, C.D.; Ravaud, A.; Mita, A.C.; et al. Avelumab, an anti-programmed death-ligand 1 antibody, in patients with refractory metastatic urothelial carcinoma: Results from a multicenter, phase Ib study. J. Clin. Oncol. 2017, 35, 2117-2124. [CrossRef]

16. Powles, T.; O’Donnell, P.H.; Massard, C.; Arkenau, H.T.; Friedlander, T.W.; Hoimes, C.J.; Lee, J.L.; Ong, M.; Sridhar, S.S.; Vogelzang, N.J.; et al. Efficacy and safety of durvalumab in locally advanced or metastatic urothelial carcinoma: Updated results from a phase 1/2 open-label study. JAMA Oncol. 2017, 3, e172411. [CrossRef]

17. Bellmunt, J.; de Wit, R.; Vaughn, D.J.; Fradet, Y.; Lee, J.L.; Fong, L.; Vogelzang, N.J.; Climent, M.A.; Petrylak, D.P.; Choueiri, T.K.; et al. Pembrolizumab as second-line therapy for advanced urothelial carcinoma. N. Engl. J. Med. 2017, 376, 1015-1026. [CrossRef]

18. Vuky, J.; Balar, A.V.; Castellano, D.; O’Donnell, P.H.; Grivas, P.; Bellmunt, J.; Powles, T.; Bajorin, D.; Hahn, N.M.; Savage, M.J.; et al. Long-term outcomes in KEYNOTE-052: Phase II study investigating first-line pembrolizumab in cisplatin-ineligible patients with locally advanced or metastatic urothelial cancer. J. Clin. Oncol. 2020, 38, 2658-2666. [CrossRef] [PubMed]

19. Powles, T.; Park, S.H.; Voog, E.; Caserta, C.; Valderrama, B.P.; Gurney, H.; Kalofonos, H.; Radulović, S.; Demey, W.; Ullén, A.; et al. Avelumab maintenance therapy for advanced or metastatic urothelial carcinoma. N. Engl. J. Med. 2020, 383, 1218-1230. [CrossRef] [PubMed]

20. Francisco, L.M.; Sage, P.T.; Sharpe, A.H. The PD-1 pathway in tolerance and autoimmunity. Immunol. Rev. 2010, 236, 219-242. [CrossRef]

21. Parry, R.V.; Chemnitz, J.M.; Frauwirth, K.A.; Lanfranco, A.R.; Braunstein, I.; Kobayashi, S.V.; Linsley, P.S.; Thompson, C.B.; Riley, J.L. CTLA-4 and PD-1 receptors inhibit T-cell activation by distinct mechanisms. Mol. Cell Biol. 2005, 25, 9543-9553. [CrossRef] [PubMed]

22. Riella, L.V.; Paterson, A.M.; Sharpe, A.H.; Chandraker, A. Role of the PD-1 pathway in the immune response. Am. J. Transplant. 2012, 12, 2575-2587. [CrossRef] [PubMed]

23. Momtaz, P.; Postow, M.A. Immunologic checkpoints in cancer therapy: Focus on the programmed death-1 (PD-1) receptor pathway. Pharmgenom. Pers Med. 2014, 7, 357-365. [CrossRef] [PubMed]

24. Massari, F.; Santoni, M.; Ciccarese, C.; Santini, D.; Alfieri, S.; Martignoni, G.; Brunelli, M.; Piva, F.; Berardi, R.; Montironi, R.; et al. PD-1 blockade therapy in renal cell carcinoma: Current studies and future promises. Cancer Treat Rev. 2015, 41, 114-121. [CrossRef]

25. Topalian, S.L.; Drake, C.G.; Pardoll, D.M. Targeting the PD-1/B7-H1(PD-L1) pathway to activate anti-tumor immunity. Curr. Opin. Immunol. 2012, 24, 207-212. [CrossRef] [PubMed]

26. Ribas, A. Tumor immunotherapy directed at PD-1. N. Engl. J. Med. 2012, 366, 2517-2519. [CrossRef]

27. Treatment by Cancer Type [Internet]. [cited 2021 June 8]. Available online: https://www.nccn.org/guidelines/category_1 (accessed on 1 July 2021).

28. EAU Guidelines I Uroweb [Internet]. [cited 2021 June 8]. Available online: https://uroweb.org/guidelines (accessed on 1 July 2021).

29. Balar, A.V.; Kulkarni, G.S.; Uchio, E.M.; Boormans, J.; Mourey, L.; Krieger, L.E.M.; Singer, E.A.; Bajorin, D.F.; Kamat, A.M.; Grivas, P.; et al. Keynote 057: Phase II trial of Pembrolizumab (pembro) for patients (pts) with high-risk (HR) nonmuscle invasive bladder cancer (NMIBC) unresponsive to Bacillus Calmette-Guérin (BCG). J. Clin. Oncol. 2019, 37 (Suppl. S7), 350. [CrossRef]

30. Balar, A.V.; Kamat, A.M.; Kulkarni, G.S.; Uchio, E.M.; Boormans, J.L.; Bajorin, D.F.; Roumiguié, M.; Singer, E.A.; Krieger, L.E.M.; Grivas, P.; et al. Pembrolizumab (pembro) for the treatment of patients with Bacillus Calmette-Guérin (BCG) unresponsive, high-risk (HR) non-muscle-invasive bladder cancer (NMIBC): Over two years follow-up of KEYNOTE-057. J. Clin. Oncol. 2020, 38 (Suppl. S15), 5041. [CrossRef]

31. Balar, A.V.; Kamat, A.M.; Kulkami, G.S.; Uchio, E.M.; Boormans, J.L.; Roumiguié, M.; Krieger, L.E.M.; Singer, E.A.; Bajorin, D.F.; Grivas, P.; et al. Pembrolizumab for the treatment of patients with high-risk (HR) non-muscle-invasive bladder cancer (NMIBC) unresponsive to Bacillus Calmette-Guérin: Extended follow-up of KEYNOTE-057 cohort A. J. Clin. Oncol. 2021, 39 (Suppl. S6), 451. [CrossRef] 
32. Black, P.C.; Tangen, C.; Singh, P.; McConkey, D.J.; Lucia, S.; Lowrance, W.T.; Koshkin, V.S.; Stratton, K.L.; Bivalacqua, T.; Sharon, E.; et al. Phase II trial of atezolizumab in BCG-unresponsive non-muscle invasive bladder cancer: SWOG S1605 (NCT \#02844816). J. Clin. Oncol. 2020, 38 (Suppl. S15), 5022. [CrossRef]

33. Kamat, A.M.; Shore, N.; Hahn, N.; Alanee, S.; Nishiyama, H.; Shariat, S.; Nam, K.; Kapadia, E.; Frenkl, T.; Steinberg, G. KEYNOTE-676: Phase III study of BCG and pembrolizumab for persistent/recurrent high-risk NMIBC. Future Oncol. 2020, 16, 507-516. [CrossRef]

34. Advanced Bladder Cancer (ABC) Meta-Analysis Collaboration. Neoadjuvant chemotherapy in invasive bladder cancer: Update of a systematic review and meta-analysis of individual patient data advanced bladder cancer (ABC) meta-analysis collaboration. Eur. Urol. 2005, 48, 202-205; discussion 205-206. [CrossRef]

35. Advanced Bladder Cancer (ABC) Meta-Analysis Collaboration. Adjuvant chemotherapy for invasive bladder cancer (individual patient data). Cochrane Database Syst. Rev. 2006, 2, CD006018. [CrossRef]

36. Patel, V.G.; Oh, W.K.; Galsky, M.D. Treatment of muscle-invasive and advanced bladder cancer in 2020. CA Cancer J. Clin. 2020, 70, 404-423. [CrossRef] [PubMed]

37. Necchi, A.; Anichini, A.; Raggi, D.; Briganti, A.; Massa, S.; Lucianò, R.; Colecchia, M.; Giannatempo, P.; Mortarini, R.; Bianchi, M.; et al. Pembrolizumab as neoadjuvant therapy before radical cystectomy in patients with muscle-invasive urothelial bladder carcinoma (PURE-01): An open-label, single-arm, phase II study. J. Clin. Oncol. 2018, 36, 3353-3360. [CrossRef] [PubMed]

38. Powles, T.; Kockx, M.; Rodriguez-Vida, A.; Duran, I.; Crabb, S.J.; Van Der Heijden, M.S.; Szabados, B.; Pous, A.F.; Gravis, G.; Herranz, U.A.; et al. Clinical efficacy and biomarker analysis of neoadjuvant atezolizumab in operable urothelial carcinoma in the ABACUS trial. Nat. Med. 2019, 25, 1706-1714. [CrossRef]

39. Gao, J.; Siefker-Radtke, A.O.; Navai, N.; Campbell, M.T.; Slack Tidwell, R.; Guo, C.; Kamat, A.M.; Matin, S.F.; Araujo, J.C.; Shah, A.Y.; et al. A pilot presurgical study evaluating anti-PD-L1 durvalumab (durva) plus anti-CTLA-4 tremelimumab (treme) in patients (pts) with high-risk muscle-invasive bladder carcinoma (MIBC) who are ineligible for cisplatin-based neoadjuvant chemotherapy (NAC). J. Clin. Oncol. 2019, 37 (Suppl. S15), 4551. [CrossRef]

40. Grande, E.; Guerrero, F.; Puente, J.; Galante, I.; Duran, I.; Dominguez, M.; Gordoa, T.A.; Burgos, J.; Font, A.; Pinto, A.; et al. DUTRENEO Trial: A randomized phase II trial of DUrvalumab and TREmelimumab versus chemotherapy as a NEOadjuvant approach to muscle-invasive urothelial bladder cancer (MIBC) patients (pts) prospectively selected by an interferon (INF)-gamma immune signature. J. Clin. Oncol. 2020, 38 (Suppl. S15), 5012. [CrossRef]

41. Van Dijk, N.; Gil-Jimenez, A.; Silina, K.; Hendricksen, K.; Smit, L.A.; de Feijter, J.M.; van Montfoort, M.L.; van Rooijen, C.; Peters, D.; Broeks, A.; et al. Preoperative ipilimumab plus nivolumab in locoregionally advanced urothelial cancer: The NABUCCO trial. Nat. Med. 2020, 26, 1839-1844. [CrossRef]

42. Rodriguez-Moreno, J.F.; de Velasco, G.; Bravo Fernandez, I.; Alvarez-Fernandez, C.; Fernandez, R.; Vazquez-Estevez, S.; Virizuela, J.A.; Gajate, P.; Font, A.; Lainez, N.; et al. Impact of the combination of durvalumab (MEDI4736) plus olaparib (AZD2281) administered prior to surgery in the molecular profile of resectable urothelial bladder cancer: NEODURVARIB Trial. J. Clin. Oncol. 2020, 38 (Suppl. S6), 542. [CrossRef]

43. Hoimes, C.J.; Adra, N.; Fleming, M.T.; Kaimakliotis, H.Z.; Picus, J.; Smith, Z.L.; Walling, R.; Trabulsi, E.J.; HoffmanCensits, J.H.; Koch, M.O.; et al. Phase Ib/II neoadjuvant (N-) pembrolizumab (P) and chemotherapy for locally advanced urothelial cancer (laUC): Final results from the cisplatin (C)- eligible cohort of HCRN GU14-188. J. Clin. Oncol. 2020, 38 (Suppl. S15), 5047. [CrossRef]

44. Kaimakliotis, H.Z.; Adra, N.; Kelly, W.K.; Trabulsi, E.J.; Lauer, R.C.; Picus, J.; Smith, Z.L.; Walling, R.; Masterson, T.A.; Calaway, A.C.; et al. Phase II neoadjuvant (N-) gemcitabine (G) and pembrolizumab (P) for locally advanced urothelial cancer (laUC): Interim results from the cisplatin (C)-ineligible cohort of GU14-188. J. Clin. Oncol. 2020, 38 (Suppl. S15), 5019. [CrossRef]

45. Gupta, S.; Sonpavde, G.; Weight, C.J.; McGregor, B.A.; Gupta, S.; Maughan, B.L.; Wei, X.X.; Gibb, E.; Thyagarajan, B.; Einstein, D.J.; et al. Results from BLASST-1 (Bladder Cancer Signal Seeking Trial) of nivolumab, gemcitabine, and cisplatin in muscle invasive bladder cancer (MIBC) undergoing cystectomy. J. Clin. Oncol. 2020, 38 (Suppl. S6), 439. [CrossRef]

46. Cathomas, R.; Petrausch, U.; Hayoz, S.; Schneider, M.; Schardt, J.A.; Seiler, R.; Erdmann, A.; Rothschild, S.; Aeppli, S.; Mach, N.; et al. Perioperative chemoimmunotherapy with durvalumab (Durva) in combination with cisplatin/gemcitabine (Cis/Gem) for operable muscle-invasive urothelial carcinoma (MIUC): Preplanned interim analysis of a single-arm phase II trial (SAKK 06/17). J. Clin. Oncol. 2020, 38 (Suppl. S6), 499. [CrossRef]

47. Galsky, M.D.; Hahn, N.M.; Rosenberg, J.E.; Sonpavde, G.; Oh, W.K.; Dreicer, R.; Vogelzang, N.J.; Sternberg, C.N.; Bajorin, D.F.; Bellmunt, J.; et al. Defining "cisplatin ineligible" patients with metastatic bladder cancer. J. Clin. Oncol. 2011, 29 (Suppl. S7), 238. [CrossRef]

48. Bellmunt, J.; Hussain, M.; Gschwend, J.E.; Albers, P.; Oudard, S.; Castellano, D.; Daneshmand, S.; Nishiyama, H.; Majchrowicz, M.; Degaonkar, V.; et al. Adjuvant atezolizumab versus observation in muscle-invasive urothelial carcinoma (IMvigor010): A multicentre, open-label, randomised, phase 3 trial. Lancet Oncol. 2021, 22, 525-537. [CrossRef]

49. Bajorin, D.F.; Witjes, J.A.; Gschwend, J.; Schenker, M.; Valderrama, B.P.; Tomita, Y.; Bamias, A.; Lebret, T.; Shariat, S.; Park, S.H.; et al. First results from the phase 3 CheckMate 274 trial of adjuvant nivolumab vs. placebo in patients who underwent radical surgery for high-risk muscle-invasive urothelial carcinoma (MIUC). J. Clin. Oncol. 2021, 39 (Suppl. S6), 391. [CrossRef]

50. Hoffman-Censits, J.; Wong, Y.N. Perioperative and maintenance therapy after first-line therapy as paradigms for drug discovery in urothelial carcinoma. Clin. Genitourin Cancer 2015, 13, 302-308. [CrossRef] 
51. Bellmunt, J.; Théodore, C.; Demkov, T.; Komyakov, B.; Sengelov, L.; Daugaard, G.; Caty, A.; Carles, J.; Jagiello-Gruszfeld, A.; Karyakin, O.; et al. Phase III trial of vinflunine plus best supportive care compared with best supportive care alone after a platinum-containing regimen in patients with advanced transitional cell carcinoma of the urothelial tract. J. Clin. Oncol. 2009, 27, 4454-4461. [CrossRef]

52. Oing, C.; Rink, M.; Oechsle, K.; Seidel, C.; von Amsberg, G.; Bokemeyer, C. Second line chemotherapy for advanced and metastatic urothelial carcinoma: Vinflunine and beyond. A comprehensive review of the current literature. J. Urol. 2016, 195, 254-263. [CrossRef]

53. De Santis, M.; Bellmunt, J.; Mead, G.; Kerst, J.M.; Leahy, M.; Maroto, P.; Gil, T.; Marreaud, S.; Daugaard, G.; Skoneczna, I.; et al. Randomized phase II/III trial assessing gemcitabine/carboplatin and methotrexate/carboplatin/vinblastine in patients with advanced urothelial cancer who are unfit for cisplatin-based chemotherapy: EORTC study 30986. J. Clin. Oncol. 2012, 30, 191-199. [CrossRef]

54. Bellmunt, J.; Powles, T.; Vogelzang, N.J. A review on the evolution of PD-1/PD-L1 immunotherapy for bladder cancer: The future is now. Cancer Treat Rev. 2017, 54, 58-67. [CrossRef]

55. Reck, M.; Rodríguez-Abreu, D.; Robinson, A.G.; Hui, R.; Csőszi, T.; Fülöp, A.; Gottfried, M.; Peled, N.; Tafreshi, A.; Cuffe, S.; et al. Pembrolizumab versus chemotherapy for PD-L1-positive non-small-cell lung cancer. N. Engl. J. Med. 2016, 375, 1823-1833. [CrossRef]

56. Bellmunt, J.; Mullane, S.A.; Werner, L.; Fay, A.P.; Callea, M.; Leow, J.J.; Taplin, M.E.; Choueiri, T.K.; Hodi, F.S.; Freeman, G.J.; et al. Association of PD-L1 expression on tumor-infiltrating mononuclear cells and overall survival in patients with urothelial carcinoma. Ann. Oncol. 2015, 26, 812-817. [CrossRef] [PubMed]

57. Ferris, R.L.; Blumenschein, G., Jr.; Fayette, J.; Guigay, J.; Colevas, A.D.; Licitra, L.; Harrington, K.; Kasper, S.; Vokes, E.E.; Even, C.; et al. Nivolumab for recurrent squamous-cell carcinoma of the head and neck. N. Engl. J. Med. 2016, 375, 1856-1867. [CrossRef] [PubMed]

58. Lopez-Beltran, A.; Cimadamore, A.; Blanca, A.; Massari, F.; Vau, N.; Scarpelli, M.; Cheng, L.; Montironi, R. Immune checkpoint inhibitors for the treatment of bladder cancer. Cancers 2021, 13, 131. [CrossRef]

59. Pierantoni, F.; Maruzzo, M.; Gardi, M.; Bezzon, E.; Gardiman, M.P.; Porreca, A.; Basso, U.; Zagonel, V. Immunotherapy and urothelial carcinoma: An overview and future prospectives. Crit. Rev. Oncol. Hematol. 2019, 143, 46-55. [CrossRef]

60. Balar, A.V.; Castellano, D.; O’Donnell, P.H.; Grivas, P.; Vuky, J.; Powles, T.; Plimack, E.R.; Hahn, N.M.; de Wit, R.; Pang, L.; et al. First-line pembrolizumab in cisplatin-ineligible patients with locally advanced and unresectable or metastatic urothelial cancer (KEYNOTE-052): A multicentre, single-arm, phase 2 study. Lancet Oncol. 2017, 18, 1483-1492. [CrossRef]

61. Powles, T.; Csőszi, T.; Özgüroğlu, M.; Matsubara, N.; Géczi, L.; Cheng, S.Y.; Fradet, Y.; Oudard, S.; Vulsteke, C.; Morales Barrera, R.; et al. KEYNOTE-361 Investigators. Pembrolizumab alone or combined with chemotherapy versus chemotherapy as first-line therapy for advanced urothelial carcinoma (KEYNOTE-361): A randomised, open-label, phase 3 trial. Lancet Oncol. 2021. [CrossRef]

62. Powles, T.; van der Heijden, M.S.; Castellano, D.; Galsky, M.D.; Loriot, Y.; Petrylak, D.P.; Ogawa, O.; Park, S.H.; Lee, J.L.; De Giorgi, U.; et al. Durvalumab alone and durvalumab plus tremelimumab versus chemotherapy in previously untreated patients with unresectable, locally advanced or metastatic urothelial carcinoma (DANUBE): A randomised, open-label, multicentre, phase 3 trial. Lancet Oncol. 2020, 21, 1574-1588. [CrossRef]

63. Galsky, M.D.; Necchi, A.; Sridhar, S.S.; Ogawa, O.; Angra, N.; Hois, S.; Xiao, F.; Goluboff, E.; Bellmunt, J. A phase III, randomized, open-label, multicenter, global study of first-line durvalumab plus standard of care (SoC) chemotherapy and durvalumab plus tremelimumab, and SoC chemotherapy versus SoC chemotherapy alone in unresectable locally advanced or metastatic urothelial cancer (NILE). J. Clin. Oncol. 2021, 39 (Suppl. S6), TPS504. [CrossRef]

64. Galsky, M.D.; Arija, J.Á.A.; Bamias, A.; Davis, I.D.; De Santis, M.; Kikuchi, E.; Garcia-Del-Muro, X.; De Giorgi, U.; Mencinger, M.; Izumi, K.; et al. Atezolizumab with or without chemotherapy in metastatic urothelial cancer (IMvigor130): A multicentre, randomised, placebo-controlled phase 3 trial. Lancet 2020, 395, 1547-1557. [CrossRef]

65. Galsky, M.D.; Mortazavi, A.; Milowsky, M.I.; George, S.; Gupta, S.; Fleming, M.T.; Dang, L.H.; Geynisman, D.M.; Walling, R.; Alter, R.S.; et al. Randomized double-blind phase II study of maintenance pembrolizumab versus placebo after first-line chemotherapy in patients with metastatic urothelial cancer. J. Clin. Oncol. 2020, 38, 1797-1806. [CrossRef]

66. Font, A.; Perez-Valderrama, B.; Virizuela, J.A.; Hernando Polo, S.; Climent, M.A.; Arranz Arija, J.A.; Villa Guzman, J.C.; del Mar Llorente, M.; Lainez, N.; Mellado, B.; et al. Randomized, placebo-controlled phase II trial (MAJA): Efficacy results of maintenance vinflunine after cisplatin chemotherapy (CT) in patients with advanced urothelial carcinoma (UC)-SOGUG 2011-02. J. Clin . Oncol. 2016, 34 (Suppl. S15), 4529. [CrossRef]

67. Hanna, K.S. Updates and novel treatments in urothelial carcinoma. J. Oncol. Pharm. Pract. 2019, 25, 648-656. [CrossRef] [PubMed]

68. Powles, T.; Durán, I.; van der Heijden, M.S.; Loriot, Y.; Vogelzang, N.J.; De Giorgi, U.; Oudard, S.; Retz, M.M.; Castellano, D.; Bamias, A.; et al. Atezolizumab versus chemotherapy in patients with platinum-treated locally advanced or metastatic urothelial carcinoma (IMvigor211): A multicentre, open-label, phase 3 randomised controlled trial. Lancet 2018, 391, 748-757. [CrossRef]

69. Sharma, P.; Callahan, M.K.; Bono, P.; Kim, J.; Spiliopoulou, P.; Calvo, E.; Pillai, R.N.; Ott, P.A.; de Braud, F.; Morse, M.; et al. Nivolumab monotherapy in recurrent metastatic urothelial carcinoma (CheckMate 032): A multicentre, open-label, two-stage, multi-arm, phase 1/2 trial. Lancet Oncol. 2016, 17, 1590-1598. [CrossRef] 
70. Roviello, G.; Catalano, M.; Nobili, S.; Santi, R.; Mini, E.; Nesi, G. Focus on biochemical and clinical predictors of response to immune checkpoint inhibitors in metastatic urothelial carcinoma: Where do we stand? Int. J. Mol. Sci. 2020, 21, 7935. [CrossRef]

71. Rosenberg, J.E.; O’Donnell, P.H.; Balar, A.V.; McGregor, B.A.; Heath, E.I.; Yu, E.Y.; Galsky, M.D.; Hahn, N.M.; Gartner, E.M.; Pinelli, J.M.; et al. Pivotal trial of enfortumab vedotin in urothelial carcinoma after platinum and anti-programmed death $1 /$ programmed death ligand 1 therapy. J. Clin. Oncol. 2019, 37, 2592-2600. [CrossRef]

72. Massard, C.; Gordon, M.S.; Sharma, S.; Rafii, S.; Wainberg, Z.A.; Luke, J.; Curiel, T.J.; Colon-Otero, G.; Hamid, O.; Sanborn, R.E.; et al. Safety and efficacy of durvalumab (MEDI4736), an anti-programmed cell death ligand-1 immune checkpoint inhibitor, in patients with advanced urothelial bladder cancer. J. Clin. Oncol. 2016, 34, 3119-3125. [CrossRef]

73. Plimack, E.R.; Bellmunt, J.; Gupta, S.; Berger, R.; Chow, L.Q.; Juco, J.; Lunceford, J.; Saraf, S.; Perini, R.F.; O’Donnell, P.H. Safety and activity of pembrolizumab in patients with locally advanced or metastatic urothelial cancer (KEYNOTE-012): A non-randomised, open-label, phase 1b study. Lancet Oncol. 2017, 18, 212-220. [CrossRef]

74. Cancer Genome Atlas Research Network. Comprehensive molecular characterization of urothelial bladder carcinoma. Nature 2014, 507, 315-322. [CrossRef]

75. Alexandrov, L.B.; Nik-Zainal, S.; Wedge, D.C.; Aparicio, S.A.; Behjati, S.; Biankin, A.V.; Bignell, G.R.; Bolli, N.; Borg, A.; Børresen-Dale, A.L.; et al. Signatures of mutational processes in human cancer. Nature 2013, 500, 415-421. [CrossRef]

76. Sjödahl, G.; Lövgren, K.; Lauss, M.; Patschan, O.; Gudjonsson, S.; Chebil, G.; Aine, M.; Eriksson, P.; Månsson, W.; Lindgren, D.; et al. Toward a molecular pathologic classification of urothelial carcinoma. Am. J. Pathol. 2013, 183, 681-691. [CrossRef] [PubMed]

77. Schumacher, T.N.; Schreiber, R.D. Neoantigens in cancer immunotherapy. Science 2015, 348, 69-74. [CrossRef] [PubMed]

78. Impact of Tumor Mutation Burden on Nivolumab Efficacy in Second-Line Urothelial Carcinoma Patients: Exploratory Analysis of the Phase II CheckMate... I OncologyPRO [Internet]. [cited 9 June 2021]. Available online: https://oncologypro.esmo. org/meeting-resources / esmo-2017-congress/Impact-of-Tumor-Mutation-Burden-on-Nivolumab-Efficacy-in-Second-LineUrothelial-Carcinoma-Patients-Exploratory-Analysis-of-the-Phase-II-CheckMate-275-Study (accessed on 1 July 2021).

79. Roh, W.; Chen, P.L.; Reuben, A.; Spencer, C.N.; Prieto, P.A.; Miller, J.P.; Gopalakrishnan, V.; Wang, F.; Cooper, Z.A.; Reddy, S.M.; et al. Integrated molecular analysis of tumor biopsies on sequential CTLA-4 and PD-1 blockade reveals markers of response and resistance. Sci. Transl. Med. 2017, 9, eaah3560. [CrossRef] [PubMed]

80. Leiserson, M.D.; Vandin, F.; Wu, H.T.; Dobson, J.R.; Eldridge, J.V.; Thomas, J.L.; Papoutsaki, A.; Kim, Y.; Niu, B.; McLellan, M.; et al. Pan-cancer network analysis identifies combinations of rare somatic mutations across pathways and protein complexes. Nat. Genet. 2015, 47, 106-114. [CrossRef]

81. Le, D.T.; Uram, J.N.; Wang, H.; Bartlett, B.R.; Kemberling, H.; Eyring, A.D.; Skora, A.D.; Luber, B.S.; Azad, N.S.; Laheru, D.; et al. PD-1 blockade in tumors with mismatch-repair deficiency. N. Engl. J. Med. 2015, 372, 2509-2520. [CrossRef]

82. Rizvi, N.A.; Hellmann, M.D.; Snyder, A.; Kvistborg, P.; Makarov, V.; Havel, J.J.; Lee, W.; Yuan, J.; Wong, P.; Ho, T.S.; et al. Cancer immunology. Mutational landscape determines sensitivity to PD-1 blockade in non-small cell lung cancer. Science 2015, 348, 124-128. [CrossRef]

83. Baker, J.B.; Dutta, D.; Watson, D.; Maddala, T.; Munneke, B.M.; Shak, S.; Rowinsky, E.K.; Xu, L.A.; Harbison, C.T.; Clark, E.A.; et al. Tumour gene expression predicts response to cetuximab in patients with KRAS wild-type metastatic colorectal cancer. $\mathrm{Br}$. $J$. Cancer 2011, 104, 488-495. [CrossRef]

84. Kim, H.K.; Choi, I.J.; Kim, C.G.; Kim, H.S.; Oshima, A.; Yamada, Y.; Arao, T.; Nishio, K.; Michalowski, A.; Green, J.E. Three-gene predictor of clinical outcome for gastric cancer patients treated with chemotherapy. Pharm. J. 2012, 12, 119-127. [CrossRef]

85. Weiss, G.R.; Grosh, W.W.; Chianese-Bullock, K.A.; Zhao, Y.; Liu, H.; Slingluff, C.L., Jr.; Marincola, F.M.; Wang, E. Molecular insights on the peripheral and intratumoral effects of systemic high-dose rIL-2 (aldesleukin) administration for the treatment of metastatic melanoma. Clin. Cancer Res. 2011, 17, 7440-7450. [CrossRef]

86. Jamieson, N.B.; Maker, A.V. Gene-expression profiling to predict responsiveness to immunotherapy. Cancer Gene Ther. 2017, 24, 134-140. [CrossRef] [PubMed]

87. Grivas, P.; Plimack, E.R.; Balar, A.V.; Castellano, D.; O’Donnell, P.H.; Bellmunt, J.; Powles, T.; Hahn, N.M.; de Wit, R.; Bajorin, D.F.; et al. Pembrolizumab as first-line therapy in cisplatin-ineligible advanced urothelial cancer (KEYNOTE-052): Outcomes in older patients by age and performance status. Eur. Urol. Oncol. 2020, 3, 351-359. [CrossRef]

88. Tang, C.; Ma, J.; Liu, X.; Liu, Z. Identification of four immune subtypes in bladder cancer based on immune gene sets. Front. Oncol. 2020, 10, 544610. [CrossRef] [PubMed]

89. Sharma, P.; Shen, Y.; Wen, S.; Yamada, S.; Jungbluth, A.A.; Gnjatic, S.; Bajorin, D.F.; Reuter, V.E.; Herr, H.; Old, L.J.; et al. CD8 tumor-infiltrating lymphocytes are predictive of survival in muscle-invasive urothelial carcinoma. Proc. Natl. Acad. Sci. USA 2007, 104, 3967-3972. [CrossRef]

90. Tran, E.; Turcotte, S.; Gros, A.; Robbins, P.F.; Lu, Y.C.; Dudley, M.E.; Wunderlich, J.R.; Somerville, R.P.; Hogan, K.; Hinrichs, C.S.; et al. Cancer immunotherapy based on mutation-specific CD4+ T cells in a patient with epithelial cancer. Science 2014, 344, 641-645. [CrossRef] [PubMed]

91. Nakanishi, J.; Wada, Y.; Matsumoto, K.; Azuma, M.; Kikuchi, K.; Ueda, S. Overexpression of B7-H1 (PD-L1) significantly associates with tumor grade and postoperative prognosis in human urothelial cancers. Cancer Immunol. Immunother. 2007, 56, 1173-1182. [CrossRef]

92. Zibelman, M.; Ramamurthy, C.; Plimack, E.R. Emerging role of immunotherapy in urothelial carcinoma-advanced disease. Urol. Oncol. 2016, 34, 538-547. [CrossRef] 
93. Wu, K.; Tan, M.Y.; Jiang, J.T.; Mu, X.Y.; Wang, J.R.; Zhou, W.J.; Wang, X.; Li, M.Q.; He, Y.Y.; Liu, Z.H. Cisplatin inhibits the progression of bladder cancer by selectively depleting G-MDSCs: A novel chemoimmunomodulating strategy. Clin. Immunol. 2018, 193, 60-69. [CrossRef]

94. McDaniel, A.S.; Alva, A.; Zhan, T.; Xiao, H.; Cao, X.; Gursky, A.; Siddiqui, J.; Chinnaiyan, A.M.; Jiang, H.; Lee, C.T.; et al. Expression of PDL1 (B7-H1) before and after neoadjuvant chemotherapy in urothelial carcinoma. Eur. Urol. Focus 2016, 1, 265-268. [CrossRef] [PubMed]

95. Sharma, P.; Siefker-Radtke, A.; de Braud, F.; Basso, U.; Calvo, E.; Bono, P.; Morse, M.A.; Ascierto, P.A.; Lopez-Martin, J.; Brossart, P.; et al. Nivolumab alone and with ipilimumab in previously treated metastatic urothelial carcinoma: CheckMate 032 nivolumab $1 \mathrm{mg} / \mathrm{kg}$ plus ipilimumab $3 \mathrm{mg} / \mathrm{kg}$ expansion cohort results. J. Clin. Oncol. 2019, 37, 1608-1616. [CrossRef]

96. Rosenberg, J.E.; Gajate, P.; Morales-Barrera, R.; Lee, J.-L.; Necchi, A.; Penel, N.; Zagonel, V.; Sierecki, M.R.; Piciu, A.-M.; Ellinghaus, P.; et al. Safety and preliminary efficacy of rogaratinib in combination with atezolizumab in a phase Ib/II study (FORT-2) of first-line treatment in cisplatin-ineligible patients (pts) with locally advanced or metastatic urothelial cancer (UC) and FGFR mRNA overexpression. J. Clin. Oncol. 2020, 38 (Suppl. S15), 5014. [CrossRef]

97. Siefker-Radtke, A.O.; Currie, G.; Abella, E.; Vaena, D.A.; Kalebasty, A.R.; Curigliano, G.; Tupikowski, K.; Andric, Z.G.; Lugowska, I.; Kelly, W.K. FIERCE-22: Clinical activity of vofatamab (V) a FGFR3 selective inhibitor in combination with pembrolizumab (P) in WT metastatic urothelial carcinoma, preliminary analysis. J. Clin. Oncol. 2019, 37 (Suppl. S15), 4511. [CrossRef]

98. Mazzola, C.R.; Chin, J. Targeting the VEGF pathway in metastatic bladder cancer. Expert Opin. Investig. Drugs 2015, 24, 913-927. [CrossRef]

99. Apolo, A.B.; da Motta Girardi, D.; Niglio, S.A.; Nadal, R.M.; Cordes, L.M.; Steinberg, S.M.; Costello, R.; Trepel, J.B.; Lee, S.; Lee, M.-J.; et al. Final results from a phase I trial and expansion cohorts of cabozantinib and nivolumab (CaboNivo) alone or with ipilimumab (CaboNivoIpi) for metastatic genitourinary tumors. J. Clin. Oncol. 2021, 39 (Suppl. S6), 3. [CrossRef]

100. Apolo, A.B.; Nadal, R.; Girardi, D.M.; Niglio, S.A.; Ley, L.; Cordes, L.M.; Steinberg, S.M.; Sierra Ortiz, O.; Cadena, J.; Diaz, C.; et al. Phase I study of cabozantinib and nivolumab alone or with ipilimumab for advanced or metastatic urothelial carcinoma and other genitourinary tumors. J. Clin. Oncol. 2020, 38, 3672-3684. [CrossRef]

101. Herbst, R.S.; Arkenau, H.T.; Santana-Davila, R.; Calvo, E.; Paz-Ares, L.; Cassier, P.A.; Bendell, J.; Penel, N.; Krebs, M.G.; MartinLiberal, J.; et al. Ramucirumab plus pembrolizumab in patients with previously treated advanced non-small-cell lung cancer, gastro-oesophageal cancer, or urothelial carcinomas (JVDF): A multicohort, non-randomised, open-label, phase 1a/b trial. Lancet Oncol. 2019, 20, 1109-1123. [CrossRef]

102. Chari, R.V. Targeted cancer therapy: Conferring specificity to cytotoxic drugs. Acc. Chem. Res. 2008, 41, 98-107. [CrossRef]

103. A Phase 1 Study of the Safety and Pharmacokinetics of Escalating Doses of ASG-22CE Given as Monotherapy in Subjects with Metastatic Urothelial Cancer and Other Malignant Solid Tumors That Express Nectin-4-AdisInsight [Internet]. [cited 9 June 2021]. Available online: https://adisinsight.springer.com/trials/700242760 (accessed on 1 July 2021).

104. Mar, N.; Friedlander, T.W.; Hoimes, C.J.; Flaig, T.W.; Bilen, M.A.; Balar, A.V.; Henry, E.; Srinivas, S.; Rosenberg, J.E.; Petrylak, D.P.; et al. Study EV-103: New randomized cohort testing enfortumab vedotin as monotherapy or in combination with pembrolizumab in locally advanced or metastatic urothelial cancer. J. Clin. Oncol. 2020, 38 (Suppl. S15), TPS5092. [CrossRef]

105. Friedlander, T.W.; Milowsky, M.I.; Bilen, M.A.; Srinivas, S.; McKay, R.R.; Flaig, T.W.; Hoimes, C.J.; Balar, A.V.; Henry, E.; Petrylak, D.P.; et al. Study EV-103: Update on durability results and long term outcome of enfortumab vedotin + pembrolizumab in first line locally advanced or metastatic urothelial carcinoma (la/mUC). J. Clin. Oncol. 2021, 39 (Suppl. S15), 4528. [CrossRef]

106. Tagawa, S.T.; Balar, A.V.; Petrylak, D.P.; Kalebasty, A.R.; Loriot, Y.; Fléchon, A.; Jain, R.K.; Agarwal, N.; Bupathi, M.; Barthelemy, P.; et al. TROPHY-U-01: A phase II open-label study of sacituzumab govitecan in patients with metastatic urothelial carcinoma progressing after platinum-based chemotherapy and checkpoint inhibitors. J. Clin. Oncol. 2021. [CrossRef] [PubMed] 